\title{
Genes de Bacillus thuringiensis: uma estratégia para conferir resistência a insetos em plantas
}

\author{
Bacillus thuringiensis genes: an approach to confer insect resistance to plants
}

\section{Vera Lucia Bobrowski ${ }^{1}$ Lidia Mariana Fiuza ${ }^{2}$ Giancarlo Pasquali ${ }^{3}$ Maria Helena Bodanese-Zanettini ${ }^{4}$}

\section{RESUMO}

Os insetos constituem uma das principais causas de danos à produção agrícola no mundo. O controle de insetos tem sido realizado por meio de agroquímicos e, em muito menor escala, pelo emprego de inseticidas biológicos. As plantas transgênicas resistentes a insetos representam uma nova alternativa no combate aos insetos-praga das lavouras. A bactéria entomopatogênica Bacillus thuringiensis Berlinier (Bt) é a fonte dos genes de resistência nas chamadas plantas-Bt, produzidas comercialmente. No presente trabalho de revisão, são abordados os aspectos relacionados à bactéria Bt como fonte de genes de resistencia a insetos-pragas, plantas geneticamente modificadas, vantagens do uso de plantas-Bt, bem como perspectivas dessa ferramenta biotecnológica.

Palavras-chave: Bacillus thuringiensis, Bt, plantas transgênicas, resistencia a insetos, insetos-praga, $\delta$ endotoxina.

\section{ABSTRACT}

Insect pests are a major worldwide cause of damage to agriculture. The control of insect pests was primarily relied on agrochemical and, in a much smaller scale, on biological insecticides. Insect-resistant transgenic plants represent a new alternative to the protection of crops against insect pests. The entomopathogenic bacterium Bacillus thuringiensis (Bt) is the source of resistance genes for the commercial production of the so called Bt-plants. In this review, the main features of Bt as source of resistance genes will be described as well as the main aspects of insect-resistant transgenic plants and advantages of using Btplants.

Key words: Bacillus thuringiensis, Bt, transgenic plants, insect resistance, insect pests, $\delta$-endotoxin.

\section{INTRODUÇÃO}

Os insetos têm sido uma das maiores causas de danos na produção de alimentos sendo estas perdas da ordem de 20 a 30\% da produção mundial (ESTRUCH et al., 1997). Estima-se que cerca de 67.000 espécies de insetos causem danos às plantações sendo as regiões tropicais, normalmente as mais pobres do mundo, as que mais sofrem com a alta incidência de insetos-praga (HERRERA-ESTRELLA, 1999). Os métodos convencionais de proteção das culturas estão baseados no uso de agroquímicos. Entretanto, mesmo com uma movimentação comercial de inseticidas em torno de U\$ 8,11 bilhões em 1997 as perdas de produção continuam altas (PEFERÖEN, 1997). A busca por métodos alternativos de controle de insetos-praga tem sido realizada com afinco por vários laboratórios ao redor do mundo, devido à necessidade de uma agricultura mais sustentável e desenvolvida com uma maior preocupação com a preservação do meio ambiente.

Os inseticidas biológicos, utilizados há mais de 50 anos no Brasil, são uma alternativa para o controle mais seletivo de insetos nocivos. Esta prática inclui, principalmente, o emprego de microorganismos. Mais recentemente, plantas transgênicas resistentes a insetos, desenvolvidas pela integração, nos seus genomas, dos genes de resistência provenientes desses microrganismos, constituem-se em mais uma alternativa com grande potencial de

\footnotetext{
${ }^{1}$ Engenheiro Agrônomo, Doutor, Professor Adjunto, Universidade Federal de Pelotas, Instituto de Biologia, Departamento de Zoologia e Genética, CP 354, 96010-900, Pelotas-RS. E-mail: vera bobrowski@ufpel.tche.br. Autor para correspondência.

${ }^{2}$ Engenheiro Agrônomo, Doutor, Professor Adjunto, Universidade do Vale do Rio dos Sinos, Centro de Ciências da Saúde, Laboratório de Microbiologia, São Leopoldo-RS.

${ }^{3}$ Farmacêutico, Doutor Professor Adjunto, Universidade Federal do Rio Grande do Sul (UFRGS), Centro de Biotecnologia do Estado do Rio Grande do Sul, Porto Alegre-RS.

${ }^{4}$ Biólogo, Doutor, Professor Titular, UFRGS, Departamento de Genética, Instituto de Biociências, Porto Alegre-RS.
} 
proteção contra as perdas causadas por insetos-praga (SCHULER et al.,1998; HILDER \& BOULTER, 1999; BETZ et al., 2000).

Mesmo sendo estudados e utilizados como biopesticidas há mais de meio século e com claras indicações de serem menos impactantes ao meio ambiente do que os agroquímicos e não prejudiciais ao ser humano, os produtos a base de Bacillus thuringiensis (Bt) nunca ocuparam um lugar de destaque no mercado de vendas de inseticidas, principalmente por problemas relacionados à perda de estabilidade, à ausência de translocação nas plantas, ao espectro limitado de ação e à degradação rápida pela ação da luz ultravioleta (NAVON, 2000). Com a clonagem e a caracterização de um gene de $\boldsymbol{B} \boldsymbol{t}$ codificador de uma proteína responsável pela atividade tóxica a insetos em 1981 (SCHNEPF \& WHITELEY, 1981), novas perspectivas do uso desta bactéria e de suas proteínas inseticidas foram vislumbradas. Entre elas, está a possibilidade de se introduzir os genes de $\boldsymbol{B} \boldsymbol{t}$ codificadores das toxinas nos genomas dos vegetais, permitindo a expressão contínua das proteínas em todos os tecidos da planta e atingindo, assim, apenas os insetos-praga que se alimentam dos tecidos (de MAAGD et al., 1999). A primeira geração de plantas transgênicas resistentes a insetos foi desenvolvida exatamente com o uso de genes codificadores de proteínas inseticidas do entomopatógeno Bt (FISCHHOFF, 1987; VAECK et al., 1987).

Além dos genes bacterianos, genes de várias outras origens têm sido introduzidos em plantas visando ao aumento do nível de resistência a danos causados por insetos. Entre os genes de resistência oriundos de plantas, incluem-se os inibidores de proteinases como, por exemplo, CII de soja (soybean serine-proteinase inhibitor), OC-I de arroz (rice cysteine-proteinase inhibitor), Pot PT-I e II de batata (potato proteinase inhibitor I e II), entre outros; inibidores de $\alpha$-amilases obtidos a partir do feijão ou de cereais; lectinas e quitinases, entre outros (SCHULER et al., 1998). Este mesmo autor cita que genes de origem animal também são utilizados como, por exemplo, o gene da anti-tripsina ( $\alpha$-antiprypsin - $\alpha-A T)$, obtido da lagarta de Manduca sexta (mandaruvá) ou de origem bovina, como o gene BPTII (bovine pancreatic trypsin inhibitor). Atualmente, cerca de 40 diferentes genes cujos produtos são capazes de conferir a resistência a insetos, foram incorporados em plantas como batata, milho, tabaco, tomate, arroz, cana-de-açúcar e algodão, entre outras (OECD, 2001).

\section{BACILLUS THURINGIENSIS COMO FONTE DE GENES}

Bacillus thuringiensis é uma bactéria gram-positiva e entomopatogênica, aeróbica ou facultativamente anaeróbica, naturalmente encontrada no solo. À semelhança de outras bactérias, esta espécie pode manter-se em latência na forma de endósporos, sob condições adversas. Durante a fase de esporulação, as bactérias sintetizam proteínas que se acumulam na periferia dos esporos na forma de cristais em um dos polos da célula (LERECLUS, 1988; HÖFTE \& WHITELEY, 1989; PEFERÖEN, 1997). Estes cristais são compostos por uma ou várias proteínas Cry, também chamadas de $\delta$-endotoxinas ou Insecticidal Crystal Proteins (ICPs). Tais proteínas são altamente tóxicas e específicas, por isso inócuas para a maioria dos outros organismos, incluindo insetos benéficos (HERRERO et al., 2001, SIEGEL, 2001).

A toxicidade de $\boldsymbol{B t}$ a insetos é devida à presença das inclusões paraesporais que apresentam formas variáveis e que se constituem de proteínas com massa variável entre 27 a $140 \mathrm{kDa}$ (AUGUSTYNIAK et al., 1997; BERHNARD et al., 1997). A maioria dos genes codificadores de $\delta$-endotoxinas estão localizados em grandes plasmídeos. Alguns dos isolados de $\boldsymbol{B} \boldsymbol{t}$ contêm mais de um gene de $\boldsymbol{\delta}$ endotoxina (KRONSTAD et al., 1983). O espectro de ação de diferentes isolados de $\boldsymbol{B} \boldsymbol{t}$ depende da combinação das $\delta$-endotoxinas individuais presentes no cristal (ESTRUCH et al., 1997). Enquanto o esporo, que representa a forma de resistência da bactéria, pode sobreviver durante vários anos, a durabilidade dos cristais é altamente variável, dependendo das condições ambientais (HÖFTE \& WHITELEY, 1989).

As $\delta$-endotoxinas constituintes dos cristais são protoxinas solubilizadas e proteoliticamente convertidas em polipeptídeos menores no trato digestivo das larvas suscetíveis (Figura 1B). Estes polipeptídeos associam-se a receptores específicos de ligação nas microvilosidades apicais das células do intestino dos insetos, causando lise osmótica por meio da formação de poros na membrana (FIUZA et al., 1996; SCHNEPF et al., 1998). O espectro de atividade inseticida destas toxinas é estreito devido ao seu modo de ação. Os sítios de ligação não somente estão envolvidos na especificidade das toxinas de $\boldsymbol{B} \boldsymbol{t}$ como também representam um mecanismo de resistência dos insetos às $\delta$-endotoxinas (FIUZA et al., 1996; de MAAGD et al., 1999).

A solubilização das proteínas depende do pH alcalino de lepidópteros e dípteros; uma menor efetividade destas proteínas em coleópteros pode ser 


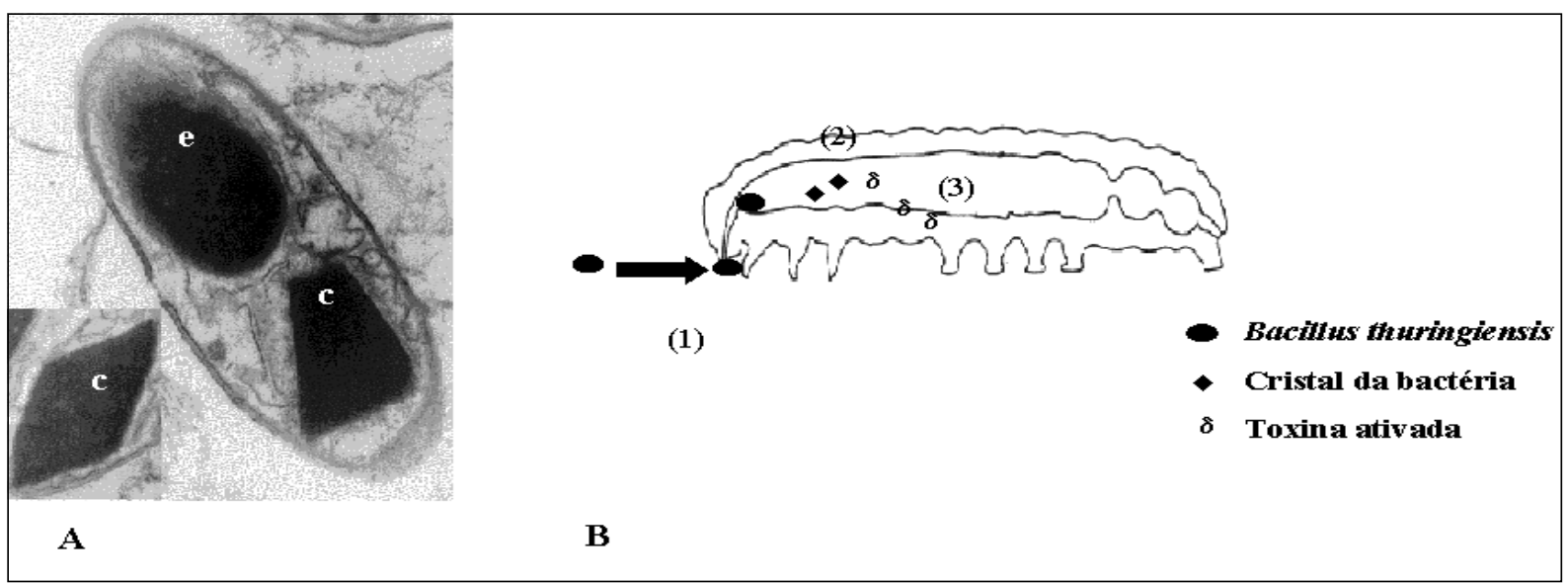

Figura 1 - O Bacillus thuringiensis e modo de ação das proteínas Cry produzidas por Bt. (A) Durante a fase de multiplicação as bactérias sintetizam proteínas (ICPs) que se acumulam na periferia dos esporos (e) na forma de cristais (c). (B) (1) Ingestão pela lagarta de esporos de $\boldsymbol{B} \boldsymbol{t}$ contendo cristais. (2) Após a ingestão da bactéria pelo inseto, os cristais são solubilizados no suco gástrico alcalino. As protoxinas constituintes dos cristais são ativadas. (3) Na região do intestino médio, as toxinas ligam-se a receptores sítio específicos do epitélio levando à formação de poros na membrana e causando a lise celular.

devida ao $\mathrm{pH}$ neutro ou pouco ácido, necessitando, então, de uma ativação in vitro (SCHNEPF et al., 1998; de MAAGD et al., 2001). Diferenças na atividade proteolítica entre os insetos-alvo podem também ser responsáveis pela especificidade das toxinas. Por exemplo, a principal protease digestiva de lepidópteros e dípteros é a serino-protease enquanto nos coleópteros ocorre principalmente cisteíno- e aspartato-proteases (de MAAGD et al., 2001). A busca de linhagens de $\boldsymbol{B} \boldsymbol{t}$ com alta atividade tóxica e diferentes especificidades a insetos é de extrema importância tanto para a produção de novos biopesticidas como para a utilização destas linhagens como fonte de genes para a obtenção de plantas geneticamente modificadas resistentes a insetos (BOBROWSKI et al., 2001).

\section{PLANTAS MODIFICADAS GENETICAMENTE COM GENES DE $B t$}

Genes de $\boldsymbol{B} \boldsymbol{t}$ codificadores de proteínas Cry foram isolados e introduzidos em plantas agronomicamente importantes utilizando diferentes métodos de transformação genética como aqueles que empregam Agrobacterium, transformação direta de protoplastos e bombardeamento de partículas ou biobalística (PASQUALI \& BODANESEZANETTINI, no prelo). Em 1981, o primeiro gene cry foi clonado e expresso em Escherichia coli (SCHNEPF \& WHITLEY, 1981). Em 1987, foi produzida a primeira planta de tomate com genes de Bt (FISCHHOFF, 1987). O milho Maximizer ${ }^{\mathrm{TM}}$ da
Novartis, o algodão Bollgard ${ }^{\mathrm{TM}}$ e a batata Newleaf ${ }^{\mathrm{TM}}$ da Monsanto foram introduzidas no mercado norteamericano em 1995, sendo genericamente conhecidas como plantas-Bt (JOUANIN et al., 1998). Atualmente, o milho-Bt é a planta transgênica mais cultivada no mundo, ocupando $15 \%$ da área global cultivada com transgênicos em países como EUA, Canadá, Argentina, África do Sul, Espanha e França. O algodão Bt ocupa o segundo lugar em áreas plantadas, representando aproximadamente $7 \%$ da área cultivada com transgênicos (JAMES, 2000). Além do milho, da batata, do tomate e do algodão, outras plantas cultivadas expressam uma ou várias proteínas Cry para o controle de lepidópteros e coleópteros (Tabela 1) e outras plantas-Bt de espécies cultivadas estão em fase de desenvolvimento em laboratórios ou em testes de campo (OECD, 2001).

Atualmente, existem mais de 200 seqüência de genes cry descritos (CRICKMORE, 2001). Especula-se que a próxima geração de plantas-Bt deverá apresentar múltiplos genes cry, oferecendo aos produtores um maior espectro de proteção contra diferentes insetos-praga e reduzindo a probabilidade dos mesmos desenvolverem resistência (BETZ et al., 2000).

ESTRUCH et al. (1997) apresentam dados indicando que plantas transformadas com genes cry $1 \mathrm{Aa}$, cry $1 \mathrm{Ab}$ e cry $1 \mathrm{Ac}$ de $\boldsymbol{B t}$, nas suas formas nativas ou truncadas, apresentam um grau de proteção não totalmente satisfatório contra Manduca sexta no tabaco, Heliothis virescens e Helicoverpa zea no tomate e Phthorimaea

Ciência Rural, v. 33, n. 5, set-out, 2003. 
Tabela 1 - Principais plantas transgênicas inseto-resistentes obtidas por meio da transferência de genes $\boldsymbol{c r y}$ de $\boldsymbol{B} \boldsymbol{t}$ (adaptado de JOUANIN et al., 1998 e SCHULER et al., 1998).

\begin{tabular}{|c|c|c|}
\hline Cultura & Gene & Inseto-alvo \\
\hline \multirow[t]{6}{*}{ Tabaco } & cry1Aa & Manduca sexta \\
\hline & $\operatorname{cry} 1 A b$ & Manduca sexta \\
\hline & cry $1 \mathrm{Ab} \&$ cryl $\mathrm{Ac}$ & Manduca sexta \\
\hline & $\operatorname{cry} 1 \mathrm{Ab}$ & Manduca sexta \\
\hline & $\operatorname{crylCa}$ & Spodoptera exigua, Spodoptera litorallis \\
\hline & $\operatorname{cry} 3 A$ & Leptinotarsa decembelineata \\
\hline \multirow[t]{2}{*}{ Tabaco-cloroplastos } & cry $1 \mathrm{Ac}$ & Heliothis virescens, Helicoverpa zea, Spodoptera exigua \\
\hline & $\operatorname{cry} 1 \mathrm{C}$ & Spodoptera littoralis \\
\hline \multirow[t]{2}{*}{ Tomate } & $\operatorname{cry} 1 \mathrm{Ab}$ & Heliothis virescens \\
\hline & $\operatorname{cry} 1 \mathrm{Ac}$ & Helicoverpa armigera \\
\hline Algodão & cry $1 \mathrm{Ab} \&$ cry $1 \mathrm{Ac}$ & Heliothis virescens, Helicoverpa zea \\
\hline \multirow[t]{2}{*}{ Batata } & $\operatorname{cry} 1 \mathrm{Ab}$ & Phthorimaea operculella \\
\hline & $\operatorname{cry} 3 \mathrm{~A}$ & Leptinotarsa decembelineata \\
\hline Alfafa & $\operatorname{cry} 1 \mathrm{Ca}$ & Spodoptera littoralis \\
\hline Canola & $\operatorname{cry} 1 \mathrm{Ac}$ & Plutella xylostella, Helicoverpa zea, Trichoplusia ni, Spodoptera exigua \\
\hline Soja & $\operatorname{cry} 1 \mathrm{Ac}$ & Heliothis virescens, Helicoverpa zea, Pseudoplusia includens \\
\hline Arroz & cry $1 \mathrm{Ab} \&$ cry $1 \mathrm{Ac}$ & Chilo suppressalis, Cnaphalocrosis medinalis, Scirpophaga incertulas \\
\hline \multirow[t]{2}{*}{ Alamo } & crylAa & Lymantria dispar \\
\hline & $\operatorname{cry} 3 \mathrm{~A}$ & Chrysomela tremulae \\
\hline Café & cry $1 \mathrm{Ac}$ & Perileucoptera coffeella, Leucoptera sp. \\
\hline \multirow[t]{2}{*}{ Milho } & cry $1 \mathrm{Ab} \&$ cry $1 \mathrm{Ac}$ & Ostrinia nubilalis \\
\hline & crylH & Ostrinia nubilalis \\
\hline Cana-de-açúcar & $\operatorname{cry} 1 \mathrm{Ab}$ & Diatraea saccharalis \\
\hline
\end{tabular}

operculella na batata (FISCHHOFF, 1987; PERLAK et al., 1990; PEFERÖEN et al., 1997). Estes trabalhos iniciais demonstraram que os genes codificadores das proteínas inseticidas de $\boldsymbol{B} \boldsymbol{t}$ podem ser expressos em plantas, mas o nível de proteínas ativas nas plantas transformadas, quando utilizados os genes nativos, é relativamente baixo, com algumas exceções (WARREN et al., 1992), o que geralmente não é suficiente para uma proteção adequada.

Em virtude dessas observações, esforços têm sido concentrados no incremento da expressão dos genes de $\boldsymbol{B} \boldsymbol{t}$ em plantas, na seleção de novas variantes de $\boldsymbol{B} \boldsymbol{t}$ mais ativas e/ou na modificação das seqüências dos genes cry de maneira a aumentar a produção de toxinas no interior das plantas. As sequências de genes cry de $\boldsymbol{B} \boldsymbol{t}$ apresentam um alto conteúdo de bases adenina/timina $(\mathrm{A} / \mathrm{T})$ quando comparados a genes de plantas, que tendem a ter um alto conteúdo de bases guanina/citosina (G/C) (de MAAGD et al., 1999). Como conseqüência, os códons preferenciais dos genes de $\boldsymbol{B t}$ são ineficientes em plantas, determinando a não tradução ou uma meia-vida do mRNA muito curta, o que leva à expressão reduzida destes genes. A substituição de nucleotídeos na seqüência codificadora por meio da síntese química ou da utilização de formas truncadas auxilia a correta leitura para tradução em plantas. Porém, devem-se adequar as modificações a cada espécie vegetal a ser transformada, tendo-se o cuidado de que a síntese (parcial ou total) gere a mesma proteína do gene nativo (ESTRUCH et al., 1997; IANNACONE et al., 1997; de MAAGD et al., 1999). No início da década de 90, foram obtidas plantas com aumento significativo da expressão dos genes de $\boldsymbol{B} \boldsymbol{t}$, capazes de conferir efetivo controle de pragas do algodão (PERLAK et al., 1990), batata (PERLAK et al., 1993; ADANG et al., 1993) e milho (KOZIEL et al., 1993), entre outras espécies (Tabela $1)$.

Outra estratégia para a maior efetividade tóxica das plantas- $\boldsymbol{B} \boldsymbol{t}$ contra insetos seria a introdução de genes nativos de $\boldsymbol{B} \boldsymbol{t}$ no genoma dos cloroplastos, o que resulta num elevado nível de expressão (SCHULER et al., 1998). A natureza procariótica dos plastídeos vegetais permite a transcrição dos genes de $\boldsymbol{B} \boldsymbol{t}$ e a tradução e processamento dos mRNAs de forma mais eficiente. Entretanto, a transformação de cloroplastos está distante de ser obtida como rotina para a maior parte das plantas e sua aplicação ainda é restrita a plantas-modelo como o tabaco e tomate (JOUANIN et al., 1998; KOTA et al., 1999). 


\section{VANTAGENS DO USO DE PLANTAS MODIFICADAS COM GENES DE $B t$}

Tendo por base os dados sobre segurança, riscos ambientais e eficiência de controle de pragas avaliados durante os 50 anos de utilização no Brasil da bactéria entomopatogênica $\boldsymbol{B} \boldsymbol{t}$ como bioinseticida, pode-se considerar que as plantas-Bt oferecem segurança e controle efetivo de insetos (de MAAGD et al., 1999). Em nível mundial, os produtores agrícolas perdem bilhões de dólares com a redução da produtividade ocasionada pelo ataque de insetos e pelo custo em defensivos agrícolas necessários para minimizar os danos. Alguns inseticidas químicos, como os piretróides sintéticos, têm sido amplamente utilizados no controle de insetos-pragas, porém estes têm perdido a eficácia devido ao surgimento de insetos resistentes (SMITH, 1999). Por outro lado, a necessidade de diminuir os custos e minimizar os efeitos ambientais e os riscos à saúde dos produtores têm tornado as plantas- $\boldsymbol{B} \boldsymbol{t}$ uma alternativa promissora para o controle de insetos.

Desde a liberação comercial das plantas$\boldsymbol{B t}$ nos EUA, os agricultores têm adotado esta tecnologia visando a um efetivo aumento de produção à agricultura sustentável (DUNWELL, 1999). Neste contexto, pode-se mencionar como benefícios do uso desta tecnologia:

\section{Diminuição dos efeitos ambientais sobre as toxinas} As plantas- $\boldsymbol{B} \boldsymbol{t}$ têm demonstrado vantagens sobre os biopesticidas pois a eficiência da produção de proteínas Cry pelas plantas-Bt não é afetada por fatores ambientais como chuva após a aplicação, incidência de radiação solar e altas temperaturas (BETZ et al., 2000). Adicionalmente, as proteínas Cry recombinantes tendem a se acumular nos tecidos vegetais de forma mais homogênea, tornando mais eficiente o efeito tóxico aos insetos do que a aplicação (pulverização) de esporos de $\boldsymbol{B} \boldsymbol{t}$ sobre as plantas.

\section{Segurança na utilização}

Várias características inerentes às plantas-

$\boldsymbol{B} \boldsymbol{t}$ proporcionam a estes produtos um grau de segurança que dificilmente pode ser obtido por meio de inseticidas formulados. Como exemplo, tem-se o fato de estas proteínas não serem tóxicas para humanos e animais domésticos, nem se acumularem nos tecidos adiposos ou persistirem no ambiente como alguns inseticidas químicos (BISHOP et al., 1999; SIEGEL, 2001). Outra característica importante é que as proteínas Cry exibem um alto grau de especificidade para os insetos-alvo e espécies relacionadas, devendo ser ingeridas para exercerem seus efeitos, uma vez que não possuem atividade por contato (BETZ et al., 2000). Este autor cita que cada classe de proteínas Cry afeta relativamente poucas espécies de insetos, principalmente nas suas fases iniciais de larva, pois a sensibilidade diminui em estádios mais tardios. Ainda outra característica relevante é que a exposição de humanos e outros animais a estas proteínas é menor do que a exposição aos inseticidas normalmente utilizados. Isto porque os inseticidas químicos e biológicos são normalmente aplicados em grandes quantidades nas folhas, enquanto as proteínas Cry, em plantas-Bt, são produzidas em pequenas quantidades no interior da planta e aparecem em níveis ainda mais baixos no pólen (BISHOP et al., 1999). O volume de inseticidas químicos ou biológicos aplicados ultrapassa enormemente a capacidade de uma planta transgênica acumular a proteína recombinante, mesmo com o uso de seqüências promotoras fortes.

\section{Redução do uso de inseticidas químicos}

Nos últimos anos, o impacto negativo dos produtos químicos sobre o meio ambiente tem se agravado com a poluição do solo e mananciais de água doce, acúmulo na cadeia alimentar e com os conseqüentes problemas de saúde pública. $\mathrm{O}$ percentual de redução nas aplicações de inseticidas químicos com o emprego de plantas-Bt foi variável, dependendo da cultura. No caso do algodão-Bt, a redução variou entre 60 e $80 \%$ na China (XIA et al., 1999) e entre 27 e $61 \%$ nos EUA (WILLIAN, 1999). Os dados de aplicação de inseticidas, em 1997, mostraram uma redução de cerca de $40 \%$ no uso de inseticidas na cultura da batata (KRATTIGER, 1997). Entretanto, segundo WILLIAN (1999), no caso do milho-Bt e da batata-Bt, mesmo com o controle das pragas principais de cada cultura, a redução nas aplicações de inseticidas não foi tão drástica devido à ocorrência de infestações de pragas secundárias, menos suscetíveis às toxinas de $\boldsymbol{B} \boldsymbol{t}$. Estas infestações de pragas secundárias acarretaram a necessidade de aplicações suplementares de inseticidas químicos.

\section{Eficiência}

HALCOMB et al. (1996) relataram que o controle efetivo de Heliothis virescens e Pectinophora gossypiella por plantas-Bt de algodão foi de 95 e $99 \%$, respectivamente, enquanto o controle de Helicoverpa armigera variou entre 70 a $90 \%$, dependendo do instar das lagartas. Experimentos a campo com milho-Bt demonstraram um controle efetivo de $99 \%$ da primeira geração de Ostrinia nubilalis (de MAAGD et al., 1999). No caso de batatas-Bt, segundo PERLAK et 
al. (1993), não houve necessidade de aplicações suplementares de inseticidas químicos para o controle do besouro Leptinotarsa decemlineata durante todo ciclo da cultura.

\section{Proteção}

A proteção inerente das plantas-Bt foi traduzida em aumento de produtividade agrícola. As perdas anuais de milho nos EUA devido aos danos causados pelo besouro L. decemlineata variavam em torno de 33 e 300 milhões de toneladas/ano e a redução destas perdas com o emprego do milho-Bt levou ao aumento da produção final de milho (BETZ et al., 2000; PEFERÖEN, 1997).

\section{Preservação de inimigos naturais}

$\mathrm{O}$ efeito das toxinas de $\boldsymbol{B} \boldsymbol{t}$ sobre inimigos naturais dos insetos-praga como parasitóides ou predadores foi estudado em laboratório e a campo, indicando pouco ou nenhum efeito sobre estes organismos (SCHULER et al., 1999; WRAIGHT et al., 2000). Os inimigos naturais são extremamente importantes, pois pragas secundárias podem tornarse um problema, caso a população de insetos benéficos for reduzida pelo uso de inseticidas químicos de amplo espectro. XIA et al. (1999) relataram que, na China, o uso de algodão- $\boldsymbol{B} \boldsymbol{t}$ determinou a redução do uso de inseticidas químicos, resultando em um aumento de $24 \%$ na população de inimigos naturais dos insetospraga, quando comparado com campos de plantas de algodão não modificadas geneticamente e submetidas ao controle químico convencional.

\section{Redução de doenças fúngicas}

As lesões causadas pelos insetos nas hastes, nas espigas e em outros órgãos das plantas promovem nítida redução na produção de grãos e oportunizam a infecção por fungos, principalmente dos gêneros Fusarium e Aspergillus (MUNKVOLD \& HELLMICH, 1999a). A germinação de esporos e a proliferação de fungos do gênero Fusarium (F. verticillioides, $F$. proliferatum ou $F$. subglutinans) normalmente estão associadas a lesões causadas pela larva de Ostrinia nubilalis (SOBEK \& MUNKVOLD, 1999). Relações similares existem entre Helicoverpa zea e Aspergillus spp. (DOWD, 1998). A importância primária destas doenças está associada às micotoxinas, particularmente fumosinas e aflatoxinas produzidas por fungos destes gêneros (MUNKVOLD \& HELLMICH, 1999b). As fumosinas podem ser fatais para eqüinos e suínos e a sua importância para a saúde humana ainda está em debate. Estudos epidemiológicos têm associado a incidência de câncer de esôfago e fígado em fazendeiros africanos com a presença de fumosinas nos alimentos (MARASAS, 1995). A aflatoxina é reconhecidamente uma micotoxina extremamente tóxica a animais e humanos. A sua presença no milho e em outros grãos tem sido monitorada pelo Food and Drug Administration dos EUA, pois a alimentação de aves e herbívoros com rações contaminadas com aflatoxinas transferiria o efeito tóxico às carnes, ovos, leite e a outros derivados alimentares para consumo humano (MUNKVOLD \& HELLMICH, 1999a). As plantas-Bt, permitindo uma drástica redução do ataque de insetos, assim como outras práticas eficientes de controle de pragas, levaram à redução da possibilidade de infecção por Fusarium e Aspergillus, e conseqüentemente, diminuiram a produção destas micotoxinas (BETZ et al., 2000).

\section{PERSPECTIVAS}

A prática do emprego de plantas-Bt tem permitido uma redução efetiva nos danos causados por insetos-praga e, simultaneamente, uma redução do uso de pesticidas químicos. Porém, a integração do uso de plantas capazes de expressar as toxinas de $\boldsymbol{B} \boldsymbol{t}$ ao sistema tradicional de cultivo de forma a evitar o desenvolvimento de resistência na população de insetos e a aceitação pública das plantas transgênicas consistem nos principais desafios a serem superados para o sucesso desta ferramenta biotecnológica que visa ao aumento da produção de alimentos de alta qualidade, baixo custo aos produtores e consumidores e reduzido impacto ambiental.

A observação de que diferentes espécies de insetos têm adquirido resistência às toxinas de $\boldsymbol{B t}$, torna necessário o isolamento e a identificação de novas proteínas de $\boldsymbol{B t}$. Igualmente importante, os estudos sobre expressão gênica, espectro de ação e especificidade das toxinas Cry, permitirão a disponibilização freqüente de novas versões gênicas mais eficazes, mais específicas e com vantagens ainda maiores sobre as práticas convencionais de controle. Neste contexto, destaca-se também a necessidade da adoção de técnicas de manejo adequadas, de forma a evitar o surgimento de resistência.

\section{REFERÊNCIAS BIBLIOGRÁFICAS}

ADANG, M.J. et al. The reconstruction and expression of a Bacillus thuringiensis cryIIIA gene in protoplasts and potato plants. Plant Molecular Biology, Dordrecht, v.21, p.1131-1145, 1993. 
AUGUSTYNIAK, J.; DABERT, M.; WYPIJEWSKI, K. Transgenes in plants: protection against viruses and insects. Acta Physiologia Plantarum, Lund, v.19, n.4, p. 561-569, 1997

BERHNARD, K. et al. Natural isolates of Bacillus thuringiensis: Worldwide distribuition, characterization, and activity against insects pests. Journal of Invertebrate Pathology, New York, v.70, p.59-68, 1997

BETZ, F.S.; HAMMOND, B.G.; FUCHS, R.L. Safety and advantages of Bacillus thuringiensis-protected plants to control insect pests. Regulatory, Toxicology and Pharmacology, San Diego, v.32, p.156-173, 2000.

BISHOP, A.H.; JOHNSON, C.; PERANI, M. The safety of Bacillus thuringiensis to mammals investigated by oral and subcutaneous dosage. World Journal of Microbiology \& Biotechnology, Amsterdam, v.15, p.375-380, 1999.

BOBROWSKI, V.L. et al. Detection of cry 1 genes in Bacillus thuringiensis isolates from south of Brazil and activity against Anticarsia gemmatalis (Lepidoptera:Noctuidae). Brazilian Journal of Microbiology, São Paulo, v.32, p.105-109, 2001.

CRICKMORE, N. Bt toxin list. Capturado em dezembro de 2001. On-line. Disponível na internet : hppt:// www.biols.susx.ac.uk/home/Neil_Crickmore/Bt/list.hmtl.

De MAAGD, R.A.; BOSCH, D.; STIEKEMA, W. Bacillus thuringiensis toxin-mediated insect resistance in plants. Trends in Plant Sciences, London, v.4, p.9-13, 1999

De MAAGD, R.A.; BRAVO, A.; CRICKMORE, N. How Bacillus thuringiensis has evolved specific toxins to colonize the insect world. Trends in Genetics, Amsterdam, v.17, n.40, p.193-199, 2001 .

DOWD, P.F. Involvement of arthropods in the establishment of mycotoxins fungi under field conditions. In: SINHA, K.K.; BHATAGNAR, D. (Eds). Mycotoxins in agriculture and food safety. New York : n.i., 1998. p.307-350.

DUNWELL, J.M. Transgenic crops: the next generation, or an example of 2020 vision. Annals of Botany, Kent, v.84, p.269277, 1999

ESTRUCH, J.J., et al. Transgenic plants: an emerging approach to pest control. Nature Biotechnology, New York, v.15, p.137$141,1997$.

FISCHHOFF, D.A. Insect tolerant transgenic tomato plants. Bio/ technology, London, v.5, p.807-813, 1987.

FIUZA, L.M., et al. Binding of Bacillus thuringiensis Cry1 toxins to the midgut brush border membrane vesicles of Chilo suppressalis (Lepidoptera:Pyralidea): evidence of shared binding sites. Applied and Environmental Microbiology, Washington, v.62, n.5, p.1544-1549, 1996.

HALCOMB, J.L. et al. Survival and growth of bollworm and tobacco budworm non-transgenic and transgenic cotton expressing CryIAc insecticidal protein (Lepidoptera : Noctuidae). Environmental Entomology, Lanham, v.25, n.2, p.250-255, 1996.

HERRERA-ESTRELLA, L. Transgenic plants for tropical regions: Some consideration about their development and their transfer to the small farmer. Proceedings of the National Academy of Sciences of the USA, Washington, v.96, p.5978-5981, 1999.
HERRERO, S.; OPPERT, B.; FERRÉ, J. Different mechanisms of resistance to Bacillus thuringiensis toxins in the indianmeal moth Applied and Environmental Microbiology, Washington, v. 67, n.3, p.1085-1089, 2001.

HILDER, V.A.; BOULTER, D. Genetic engeneering of crop plants for insect resistance - a critical review. Crop Protection, Oxford, v.18, p.177-191, 1999.

HÖFTE, H.; WHITELEY, H.R. Insecticidal crystal proteins of Bacillus thuringiensis. Microbiological Reviews, Washington, v.53, p.242-255, 1989.

IANNACONE, R.; GRIECOP, D.; CELLINI, F. Specific sequence modifications of a cry $3 \mathrm{~b}$ endotoxin gene result in high levels of expression and insect resistance. Plant Molecular Biology, Dordrecht, v.34, n.3, p.485-496, 1997.

JAMES, C. Global status of commercialized transgenic crops: 2000. ISAAA Briefs, ISAAA, Ithaca, n.21, p.45, 2000.

JOUANIN, L. et al. Transgenic plants for insect resistence-review. Plant Science, Shannom, v.131, p.1-11, 1998.

KOTA, M. et al. Overexpression of the Bacillus thuringiensis (Bt) Cry2Aa2 protein in chloroplasts confers resistance to plants against susceptible and $\boldsymbol{B t}$-resistant insects. Proceedings of the National Academy of Sciences of the USA, Washington, v.96, p.1840-1845, 1999.

KOZIEL, M.G. et al. Field performance of elite transgenic maize plants expressing an insecticidal protein derived from Bacillus thuringiensis. Bio/technology, London, v.11, p.194-200, 1993.

KRATTIGER, A.F. Insect resistance crops: a case study of Bacillus thuringiensis (Bt) and its transfer to developing countries. ISAAA Briefs, ISAAA, Ithaca, n.2, p.1-42, 1997.

KRONSTAD, J.W.; SCHNEPF, H.E.; WHITELEY, H.R. Diversity of locations for Bacillus thuringiensis crystal protein genes. Journal of Bacteriology, Washington, v.154, n.1, p.419-428, 1983.

LERECLUS, D. Génétique et biologie moléculaire de Bacillus thuringiensis. Bulletin de l'Institut Pasteur, Paris, v.86, p.337371, 1988.

MARASAS, W.F.O. Fumosins: their implications for human and animal health. Natural Toxins, Somerset, v.3, p.193-198, 1995.

MUNKVOLD, G.P.; HELLMICH, R.L. Comparison of fumosin concentrations in kernel of transgenic Bt maize hybrids and nontransgenic hybrids. Plant Disease, St. Paul, v.83, p.130-138, 1999a.

MUNKVOLD, G.P.; HELLMICH, R.L. Genetically modified insect resistant corn: implications for disease management. 1999b. Capturado da internet em dezembro de 2001. On-line. Disponível no site http://www.apsnet.org/online/feature/BtCorn/ Top.html.

NAVON, A. Bacillus thuringiensis insecticides in crop protection - reality and prospects. Crop Protection, Oxford, v.19, p.669676, 2000.

OECD, 2001. Transgenic plants registration. Capturado da internet em dezembro de 2001. On-Line. Disponível no site: http:/ /www.oecd.gov.

Ciência Rural, v. 33, n. 5, set-out, 2003. 
PASQUALI, G.; BODANESE-ZANETTINI, M.H. Transformação genética de plantas. In: FREITAS, L.B.; BERED F. (Eds). Genética Vegetal. Porto Alegre : UFRGS, 2002 ( no prelo).

PEFERÖEN, M. Progress and prospects for field use of $\boldsymbol{B} \boldsymbol{t}$ genes in crops. Trends in Biotechnology, Cambridge, v.15, p.173-177, 1997.

PERLAK, F.J. et al. Insect resistant cotton plants. Bio/technology, London, v.8, p.939-943, 1990.

PERLAK, F.J. et al. Genetically improved potato protection from damage by Colorado potato beetle. Plant Molecular Biology, Dordrecht, v.22, p.313-321, 1993.

SCHNEPF, E. et al. Bacillus thuringiensis and its pesticidal crystal proteins. Microbiology and Molecular Biology Reviews, Durham, v.62, n.3, p.775-806, 1998.

SCHNEPF, E.; WHITELEY, H.R. Cloning and expression of the Bacillus thuringiensis crystal protein gene in Escherichia coli. Proceedings of the National Academy of Sciences of the USA, Washington, v.78, p.2893-2897, 1981 .

SCHULER, T.H. et al. Insect-resistant transgenic plants. Trends in Biotechnology, Cambridge, v.16, p.168-174.1998.

SCHULER, T.H. et al. Potential side effects of insectresistant transgenic plants on arthropod natural enemies. Trends in Biotechnology, Cambridge, v.17, p.210-215, 1999.
SIEGEL, J.P. The mammalian safety of Bacillus thuringiensisbased insecticides. Journal of Invertebrate Pathology, New York, v.77, p.13-21, 2001.

SMITH, R.H. Alabama entomologist believes genetic engeneering and eradication will usher in a new era of cotton pests. Cotton Grower Plus, USA, March, v.1, p.5, 1999.

SOBEK, E.A.; MUNKVOLD, G.P. European corn borer (Lepidoptera:Pyralidae) larvae as vectors of Fusarium moniliforme, causing kernel rot and symptomless infection of maize kernels. Journal of Economic Entomology, Maryland, v.92, p.503-509,1999.

VAECK, M. et al. Transgenic plants protected from insect attack. Nature, New York, v.327, p.33-37,1987.

WARREN, G.W. et al. Field evaluation of transgenic tobacco containing a Bacillus thuringiensis insecticidal protein gene. Journal of Economical Entomology, Maryland, v.5, p.1651-1659, 1992.

WRAIGHT, C.L. et al. Absence of toxicity of Bacillus thuringiensis pollen to black swallowtails under field conditions. Proccedings of the National Academy of Sciences of the USA, Washington, v.97, n.14, p.7700-7703, 2000.

WILLIAN, M.R. Cotton insect losses 1979-1996. Capturado em junho de 1999. On-line. Disponível na internet: http:// www.msstate.edu/Entomology/CTNLOSS/1998loss.html.

XIA, J.Y. et al. The role of transgenic Bt cotton in integrated insect pest management. Acta Gossypiium Simposium, Pequim, v.11, p.57-64, 1999. 